\title{
A Systematic Literature Review of Flexible E-Procurement Marketplace
}

\section{Sara Robaty Shirzad ${ }^{1}$ and David Bell ${ }^{2}$} Brunel University, Information Systems and Computing, London, UK, ${ }^{1}$ Sara.robaty.shirzad@brunel.ac.uk,
${ }^{2}$ David.bell@brunel.ac.uk

Received 31 May 2012; received in revised form 24 January 2013; accepted 28 January 2013

\section{Abstract}

During the Web era e-procurement has witnessed a steep rise in marketplace deployment; this has been followed by a substantial number of failures. A number of larger technology providers are now left to support both small and large businesses. Flexibility has been a key enabler in supporting network evolution across a varied number of domains. The aim of this study is to investigate flexibility around marketplace evolution, success and failure. In particular, explore the inter-relationships between architectural flexibility and the evolving Web and Internet. A systematic literature review (SLR) was carried out in order to uncover the changes that have taken place over the past fifteen years. A conceptual model is produced early in the research in order to provide contextual underpinning. We employed a manual search of 5 journals. Of the 22 relevant studies, one addressed research trends around e-procurement in pharmaceutical organizations. Three addressed eprocurement in financial organizations. A number of flexibility categories are uncovered by the SLR and then used as a means to support flexible e-procurement marketplace (EPM) design and adoption, recognising EPM evolution over the volatile study period. Flexibility categories are uncovered and comprise technical, organisational, environmental and strategic (TOES) concerns.

Keywords: Systematic literature review, E-procurement, Marketplace, E-procurement marketplaces (EPM), Flexibility 


\section{Introduction}

Considerable research has been conducted on electronic procurement marketplace (EPM) over the past fifteen years. This topic has been a prominent feature of the information systems research landscape over this period with a rapid growth and later consolidation in marketplace numbers. Unsurprisingly, this EPM volatility has occurred during the early evolution of the Web. The systematic literature review presented here explores and presents the interrelationships between EPM research during this period and the changes and focus in the domains and characteristics considered important. Flexibility is highlighted as a key factor when considering which marketplace platforms to use - providing an opportunity for firms to increase overall performance and better facilitate interorganizational relationships and transactions [23]. Moreover, organizations are able to re-orientate to focus on the EPM's as opposed to traditional hierarchy-based economic activities and decision making. In unison with corporate change, the Internet has changed the way in which organizations do business by the reshaping of traditional buyingselling relationships, improving core processes, requirements and providing opportunities to reach new markets. Globalization, deregulation, increased competition, mergers and acquisitions, and the like all reveal organizations in transition, adapting to a continuously changing business environment [69]. In this dynamic context, in order to be responsive to changes in business requirements and environments, EPMs must provide quality products, services and processes in order to gain market presence and competitive edge. One could infer that marketplace flexibility is required to meet the quality needs of a diverse range of customers. Given that just over a decade of EPM research has been conducted, we argue that it is timely to take stock of the wealth of research on EPM's understand the evolution and analyze the need for future research within this field.

In its simplest form an EPM (sometime referred to as auction, exchange and catalogue aggregator) can be defined as an online intermediary networked information systems through which multiple buyers and sellers interact, exchange information about prices, product offerings, facilitate transactions between them and generally creating markets for corporate purchases [63], [90]. They typically facilitate trading activity between partners who have not had prior interaction. EPMs impact the three-sided relationships of buyers, sellers and an e-marketplace provider [94]. Attention from both research and practitioner communities is largely due to EPMs providing a relatively cost effective platform for companies to enhance transaction cost efficiency and improve supply chain performance [6]. In recent years, e-procurement and the e-marketplace have penetrated into a number of new domains such as manufacturing, pharmaceutical, finance. Along with efficiency, promptness, and ease of use, early adopters have become proficient in web-based procurement systems [23]. More firms are adopting e-procurement marketplace trading in order to achieve additional effectiveness and efficiency, with the majority of firms being satisfied with its performance [85]. Consequently, interaction with e-marketplaces are often important components a firm's procurement and sales activities.

The growing interest in EPM's in the research literature has been accompanied by an acknowledgement that the failure rate of such intermediaries is high [40], [50], [91], [93]. In January 2010, EmarketServices (Site 3) published evidence of this failure with around 650 electronic marketplaces currently in operation. This represents a decrease from 1500 electronic marketplaces in 2000 [91]. A number of reasons have been highlighted: Marketplace trust can lead to greater perceived risk and privacy concerns [24] or performance in sales, customer satisfaction and relationship development [24], [99] and efficiency and effectiveness [11]. Those EPMs that remain offer a more viable and sustainable business model for organizations to consider [70]. Rapid changes of technology in EPMs have resulted in more frequent system changes and in many cases resulted in a decision to outsource some of the IS functions [69]. Changes in technology have increased pressure on EPMs and organizations to be more responsive and flexible. Moreover, the flow of failure in some EPM's and the success of others have led business managers to question the relative merits of each EPM. Flexibility in emerging organizational networks is also a concern [45]. Hence, in order for both the organizations and EPMs as a whole to remain agile and competitive, it is important to have a better understanding of flexibility in EPMs.

The absence of a systematic process that examines flexibility in EPMs from a broader perspective analyzes is still matter of concern. The question is how an EPM can be made more flexible in order to support change and evolution when matching requirements. In order to address this gap, we synthesize current literature in a way that allows the reader to make decisions about EPM choice with respect to required flexibility. A formal systematic literature review provides a longitudinal study, synthesizing both flexibility factors and domains of deployment. The following questions are addressed in this study: RQ1: How has EPM evolved since 1995? RQ2: What are the key characteristics of EPM? RQ3: what are the flexibility issues that limit EPM evolution? RQ4: What are the architectural elements of a flexible e-procurement marketplace? In unison, a conceptual model depicting the element of EPMs is developed from the literature as both a means of synthesis and contextual grounding.

A number of popular studies have addressed this issue. We recommend this paper to those interested in a holistic and temporal view of the subject, mitigating risk associated with wrong marketplace strategy or choice. Over recent times a lot of changes have occurred in this area, understanding this volatility should be the matter of importance. EPM variability in terms of design and methodology makes it difficult to extract a coherent, dependable list of flexibility factors which in turn limits the examination of organizations requirements. 
This paper begins with a literature review of the e-procurement marketplace, flexibility domains and Web evolution. A conceptual framework is presented in order to fully understand the constituent element and factors that are in turn discussed. The method adopted for the study is then described. A summary and discussion of the study is then covered.

\section{Theoretical Foundations}

With the large amount of information potentially available to organizations, the internet has become a prominent platform for information exchange between the consumers and industry suppliers, intermediaries, as well as organizations which are not have experience of being in the e-marketplaces. A number of differing technological interfaces, such as search engines and intermediaries, facilitate the exchange of marketing information between online organizations. In order to provide some context, we critically review the literature on e-procurement emarketplaces and flexibility.

\subsection{E-Procurement Marketplace}

Until the late 1980s, the majority of buyer-seller relationships have been conducted in an arms-length manner, and typically adversarial in the sense that both, customer and supplier, tried to achieve a profitable deal at their opponents expense [24]. Importantly, this has changed over the last ten years to one where the customer-supplier relationship is actively managed. This closer relationship between stakeholders has evolved at a time when the Web has supported the growth and decline in marketplaces. This has been particularly clear in the case of one of the vital e-commerce areas, B2B electronic marketplaces [5]. B2B e-marketplaces, also known as e-procurement marketplace, electronic supply chains, trading hubs, or trading communities, are essentially web-based procurement networks in which one or more companies try to source their suppliers at the lowest costs possible [76]. EPM electronically provided value added communication, brokerage and integration services to customers as buyers and suppliers through handling of procurement processes using information and communication technologies, particularly with the help of the Internet [21]. By making this process web-based, EPM providers are changing the process in ways that go far beyond its mere computerization and automation [4]. Companies are able to source products and services at the lowest cost, while ensuring that those inputs match technical and other (tender) specifications [76].

With the potential of EPMs to improve effectiveness and efficiency, a considerable number of marketplaces were launched in the dot.com boom period of the late 1990s. Their significance has not diminished since the dot.com crash and the subsequent of many minor EPM between 2001-2003 [95], such as Efdex, Fyffes and Just2Clicks. Although the majority of these e-marketplaces launched in the past decade have failed, hundreds have survived and in some cases thrived [66]. There are many successful EPMs which are still growing in transactions, such as Alibaba Global Healthcare exchange and cc-hubwoo. Alibaba.com manages an industry specific e-marketplace that has become the world's largest e-marketplace [66]. Global Healthcare Exchange (GHX) is another, the world's largest EPM in the health-care [93]. Cc-hubwoo is the leading global provider for source-to-pay electronic solutions and supplier network management. The company manages the largest B2B e-procurement community in the world with more than 60 buying corporations and over 12.000 connected suppliers in 44 countries worldwide [95]. Cc-hubwoo's trading hub processes 2 million purchase orders representing $\$ 5$ billion in customer spend value annually. Flexibility is required in order to grow customer numbers, transactions and industry domain support.

A motivating factor for EPM deployment is a relatively low cost and the resulting enhanced transaction cost efficiency, improving performance of purchasing rights which are: at the right price, delivered at the right time, of the right quality, of the right quantity and from the right source [6], [56], [90], [107]. Figure 1 illustrates an embryonic conceptual framework of an EPM that enables customers and suppliers to submit their requirements and fulfill the demand in lowest time and budget. 


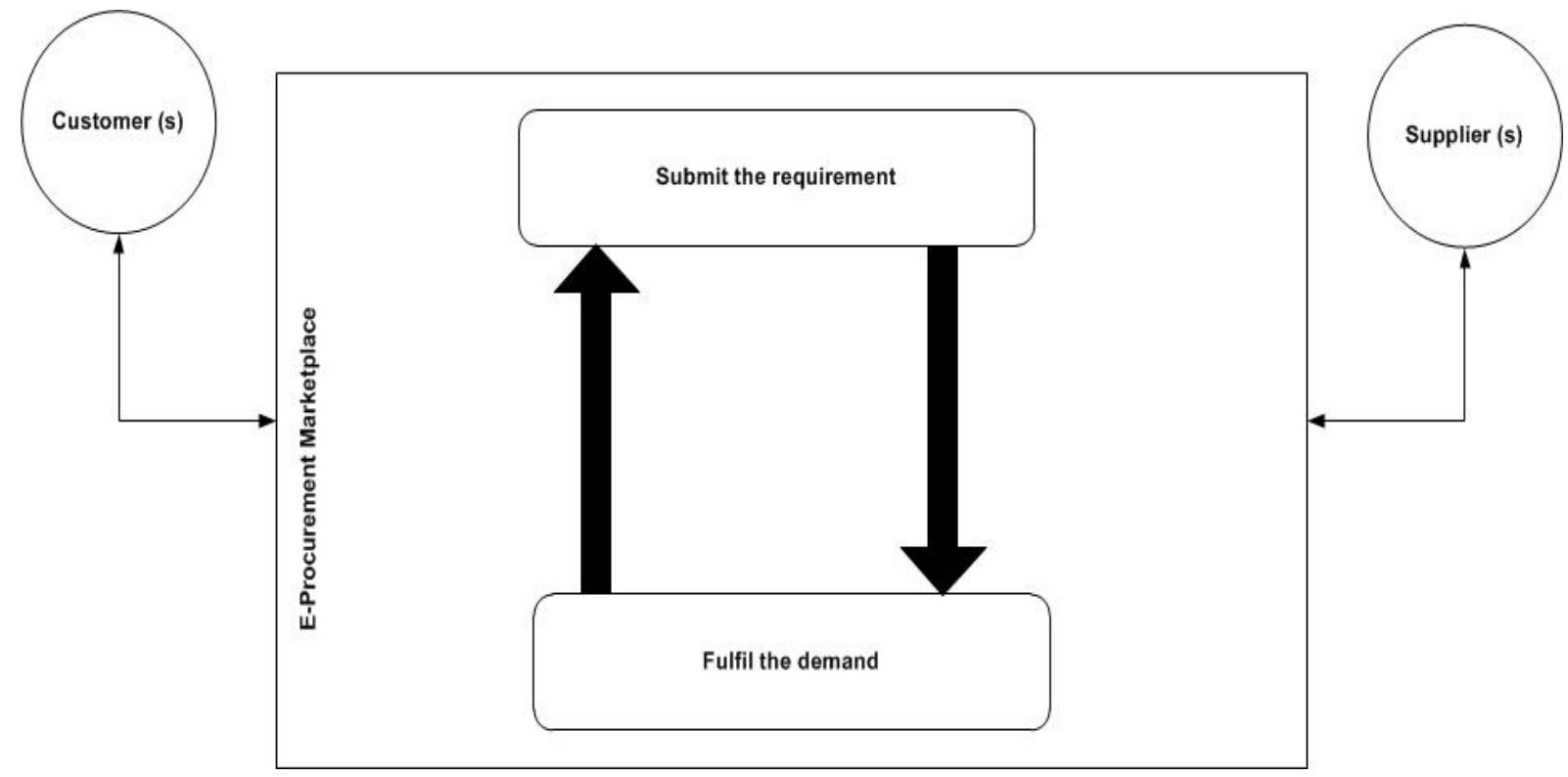

Figure 1: E-procurement marketplace

With increasing corporate procurement and selling completed on-line every day, the number of e-marketplaces worldwide soared during the years preceding and beyond the millennium [66]. One of the reasons is that further technological development and advancement is occurring at a faster pace, resulting in new product innovations and improvements in manufacturing processes. Surprisingly though, rapid and ongoing change is surpassed by the rate of failure. Customers are demanding more variety, better quality and service including both reliability and faster delivery [33]. Reduction in the number of EPMs has resulted in some advantages for both customers and suppliers. For customers, the more suppliers active within an electronic market, the more purchasing alternatives become available. Opportunities to determine market price sensitivity and reduced search costs provided by Internet technologies [56], [90]. For suppliers, the more buyers in an e-marketplace, the more customers reach for their products, improved opportunities to sell excessive inventory and gather available market intelligence - all resulting in an improved likelihood of increasing sells [6], [29], [31], [96], and [107].

In contrast, the reduction and focus on fewer EPMs can result in small changes in procurement processes (either internal system or external customers and suppliers) causing a major impact on the entire chain. In order to mitigate these affects a flexible system is expected to provide timely delivery when changing conditions occur, including changes in the short term demand [45]. Unsurprisingly, a major concern of procurement managers is to respond to and deal with changes more effectively. Basically, it is how to manage the whole marketplace when the changes have been occurred [45]. Indeed, by looking at the literature, it is clear that many authors over the last decade have focused on changes to EPM, although few have considered how flexibility can be achieved. Eid et al. [35] categorized flexibility into: marketing strategy, website, IT, technical support, global, internal, and external. Researchers are using the word flexibility to define different types of changes. The flexibility types offered so far address flexibility partially, with primary focus on infrastructure and system. Furthermore, the issues of relationships and tradeoffs between flexibility types and the strategic pathway for managing flexibility on the EPM have not been adequately addressed.

In business we see a more complex environment, increased competition, global challenges, and market shifts together with rapid technological developments (e.g., [10]), and the increasing importance of the world wide web and electronic commerce. Vokurka and O'Leary-Kelly [105] categorized these challenges of the organization into four different categories: organizational, environmental, strategic and technical in EPM.

Flexibility is the main challenge of the organizations. There has been little work on how to manage flexibility of EPM and further research is needed into how EPM can be used in organizations more synergistically. The requirement for flexibility across the EPM must be better understood and its dimensions uncovered in order to better define flexible market-based e-procurement.

\subsection{Flexibility}

The term flexible is defined in Oxford dictionary as ready and able to change so as to adapt to different circumstances. Upton [102] describes flexibility as an ability to adapt to changing conditions that helps ensure continuity of the organization and rapidly respond to changes, coming from inside as well as outside the system. Evans [38] discusses different terms that have been used instead of flexibility such as agility, elasticity, robustness 
and versatility. It is important to note that there are no universally agreed definitions on flexibility [77]. Fitzgerald [43] considered flexibility as a necessary characteristic for organizations to deal with the threats and opportunities that are brought about by the increasing dynamics and complexity of environments. In manufacturing, flexibility is defined in terms of range, mobility and uniformity, i.e. the various states a system can adopt, the ability to move from making one product to making another and the ability to perform comparably well when making any product within a specified range [89], [102]-[103].

Flexibility has been studied from an overall organizational, a manufacturing and an IS perspective. Indeed, in looking at the literature it is clear that many authors outline a number of taxonomies addressing different types of flexibility such as functional aspects i.e. flexibility in operations, marketing, logistics [47], [58], hierarchical aspects such as flexibility at shop, plant or company level [47], [52], [61] and [89], measurement aspects focused on global flexibility measures vs. context specific ones (e.g., [28], [47], [51]-[52] and [87]), strategic aspects centered on the strategic relevance of flexibility [22], [47], [49], [72] and time horizon aspects for example long-term vs. Short-term flexibility [47], [110].

Table 1: Summery of flexibility literature (adapted from Behrsin et al. [9])

\begin{tabular}{|l|l|l|}
\hline Authors (year) & Flexibility type & $\begin{array}{l}\text { Relevant contributions } \\
\text { performance }\end{array}$ \\
\hline Fiegenbaum, A. [41] & Environmental Factors & Operations \\
\hline Parthasarthy, R. [81] & Strategy and organizational factors & Market, industry operations \\
\hline Ettlie, J.E. [37] & Strategy & New design, market, operation \\
\hline Lee et al. [65] & Environmental & Human factors \\
\hline Das \& Elango [32] & Strategic & Strategy \\
\hline Upton, D.M. [103] & Organizational and Strategy factors & Operations, new design, resource \\
\hline Nilsson, C.H. [75] & Strategy, environment & $\begin{array}{l}\text { Resources, market, buyer/supplier } \\
\text { relations }\end{array}$ \\
\hline Duncan [34] & Technical & IT infrastructure \\
\hline Safizadeh, M.H. [86] & Technology factors & Product, new technology \\
\hline Suarez, F.F. [98] & Organizational and Technology factors & $\begin{array}{l}\text { new product, buyer/supplier } \\
\text { relationships, operations }\end{array}$ \\
\hline Broadbent \& Weill [14] & Technical, environmental & IT infrastructure, human factors \\
\hline Upton, D.M. [103] & Organizational and Technology factors & Operations, new product \\
\hline Broadbent et al. [15] & Technical & IT infrastructure \\
\hline Ward, P.T. [108] & Environmental and strategy factors & $\begin{array}{l}\text { Market, resource, buyer/supplier } \\
\text { requirements }\end{array}$ \\
\hline Byrd \& Tuner [17] & Environmental & Human factors \\
\hline Evans [38] & Technical & IT infrastructure \\
\hline & &
\end{tabular}

Flexibility has been an important topic of interest to researchers in the area of operations management and extensively in the context of flexibility in manufacturing systems [49], [88]-[89]. The early frameworks of manufacturing flexibility are typically dependent on the internal operations and external environment [49], [88]-[89]. Slack [89] describes five components of flexibility in marketplace (new product; product mix; quality; volume and delivery). In 1987, he further stated that different types of flexibility are more important in some environments than in others. In 1988, he designed hierarchal framework of flexibility to show that different competitive strategies will require different form of manufacturing flexibility in order to improve the firm's competitive performance. In 2005, he modified the version of a previously presented hierarchy of flexibility. His new framework is suggested that availability, productivity and dependability are incorporated into a flexibility hierarchy which links companies' competitiveness with resource level decisions concerning operational flexibility. Gerwin [49] describes seven types of flexibility which are production equipment, product design, work organization, planning and control procedures and materials management and information technology in marketplace domain. He worked on environmental uncertainty aspects and designed the conceptual framework from strategy to environmental uncertainty and to flexibility. He stated a company may reduce environmental uncertainty through, for example, long-term contracts with customers and suppliers, design for manufacturability, preventive maintenance, and total quality control. Vokurka and O'LearyKelly [105] expanded different dimensions developed by Browne et al. [16] and Sethi and Sethi [88] on manufacturing flexibility to fifteen elements (machine; material handling; operations; automation; labor; process; routing; product; new design; delivery; volume; expansion; program; production and market). The main six components of supply chain flexibility indicated by Duclos et al. [33] are operations systems flexibility, market flexibility, supply flexibility, logistics flexibility, organizational flexibility and information system flexibility. He also proposed the framework for supply chain flexibility based on these dimensions. Parthasarthy and Sethi's [81] 
strategic flexibility framework also included the industries technological environment and its organizational structure. In 1995, Nilsson used the term external flexibility for issues concerning rigidity in the relationship between the company and the outside environment describing two types: output flexibilities which are found in the relationship between the company and its customers and input flexibilities which are found in the relationship between company and its suppliers ([75]). The framework started with description about input transform output (ITO) model. It describes the flow of goods from suppliers, transformation process and on the customers. The limitation of this model is its singular focus on one dimension of manufacturing - labor flexibility. In fact, it can be seen in the literature that most of the frameworks address interrelationship in a limited form; Table one summarizes the important frameworks and the type of the flexibilities they address from 1987 to 2002.

Early approaches to manufacturing flexibility had a bottom-up structure which meant that it evolved out of the basic flexibility types with respect to components such as volume flexibility [16], [45], [81], [88] and [89]. In more recent years, research on manufacturing flexibility considered top-down hierarchal structures and viewed flexibility in terms of manufacturing strategy or through a market perspective [7], [45]. Table 1 summarizes the variety of reasons in why we need to consider flexibility as an important context.

Examination of past studies present four general areas (technological, organizational, environmental and strategic) that comprise the dominant forces influencing flexibility in manufacturing. Although these frameworks address the important relationship between manufacturing flexibility and one or two other flexibilities, they do not address the other equally important relationships involving manufacturing flexibility and technical, organizational, environmental and strategy. This study refers to them as TOES concerns. Frequent calls are made from users/suppliers for those aspects to be more flexible, particularly in the face of turbulent environments. We deem that it is easier to visualize type of changes by associating them with flexibility aspects. Figure 2 illustrates the flexibility dimensions derived from literature.

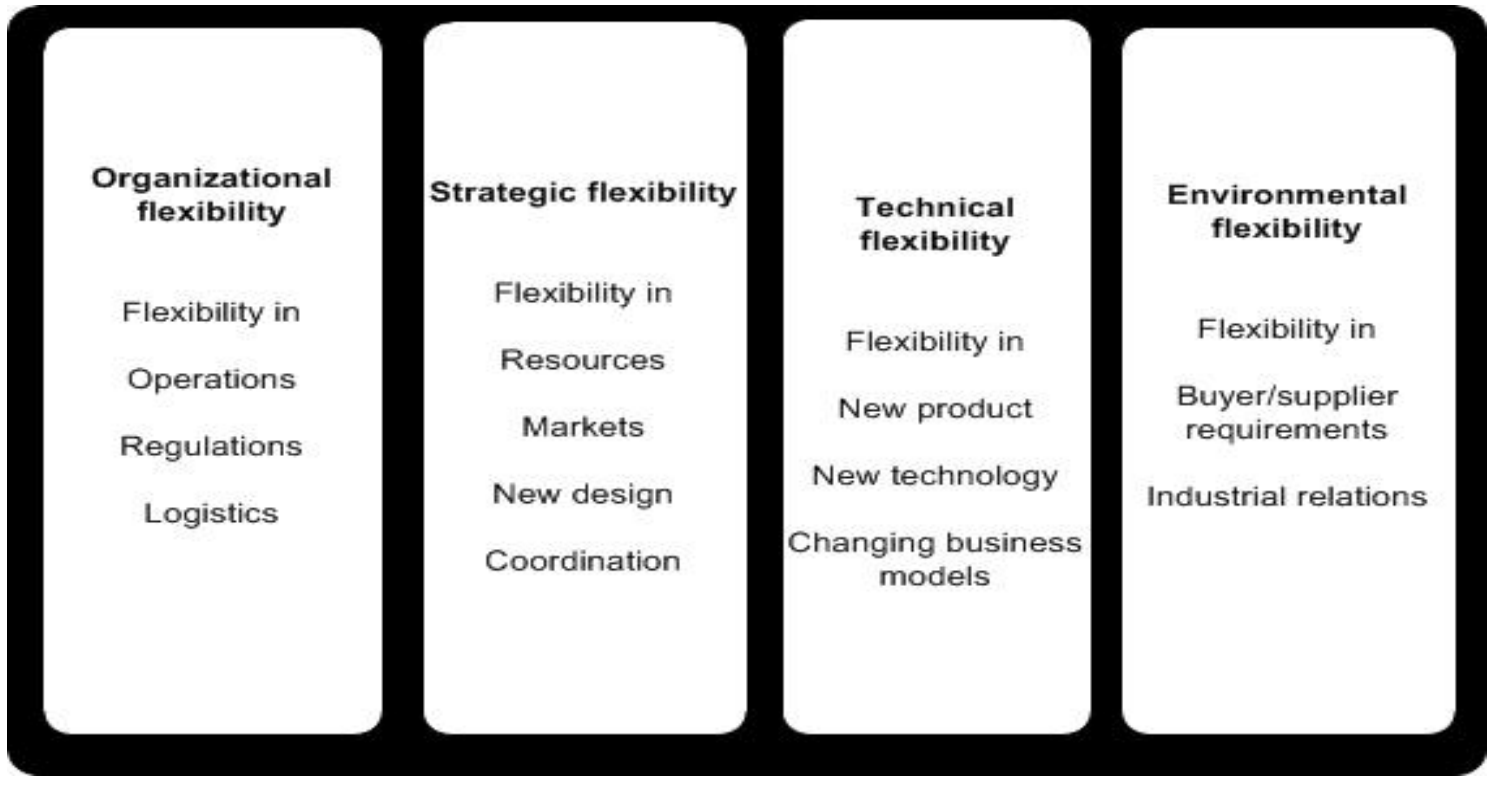

Figure 2: TOES concerns

Whether formulating strategy or developing IS architecture, flexibility is regarded as extremely important [1], [45], [49], [53]. From the literature on manufacturing flexibility, a number of elements can be identified that might usefully be applied to EPM. Firstly, flexibility appears to be a critical element of success in manufacturing. Second, flexibility can be applied at a number of internally or externally levels, for example, to cover both internal level (organizational, strategic) of the organization (marketplace) and external level (environmental). Furthermore, in order to build a system for online business, a number of hardware and software applications need to be synchronized, as Vizared [104] stated. This is why Ozer [78] reported the fact that online firms are acquired flexible technologies that allow them to add new applications to their systems (technical). We are aiming to cover both internal and external level of the organization (marketplace).

\subsection{From Web Evolution to Development of Flexible EPM}

In order to better understand the relationships between flexibility and EPM, we analyzed the Web evolution with respect to EPM flexibility.

The Web has undergone a number of evolutions in its short lifetime. Here, we refer to the period before 1990 as the pre-Web era, the early 1990 s as the reactive Web era, the mid-1990s as the interactive Web era, and the period 
around the start of the 21st century as the integrative Web era. This terminology was taken from Chu [27], presented in figure 3.

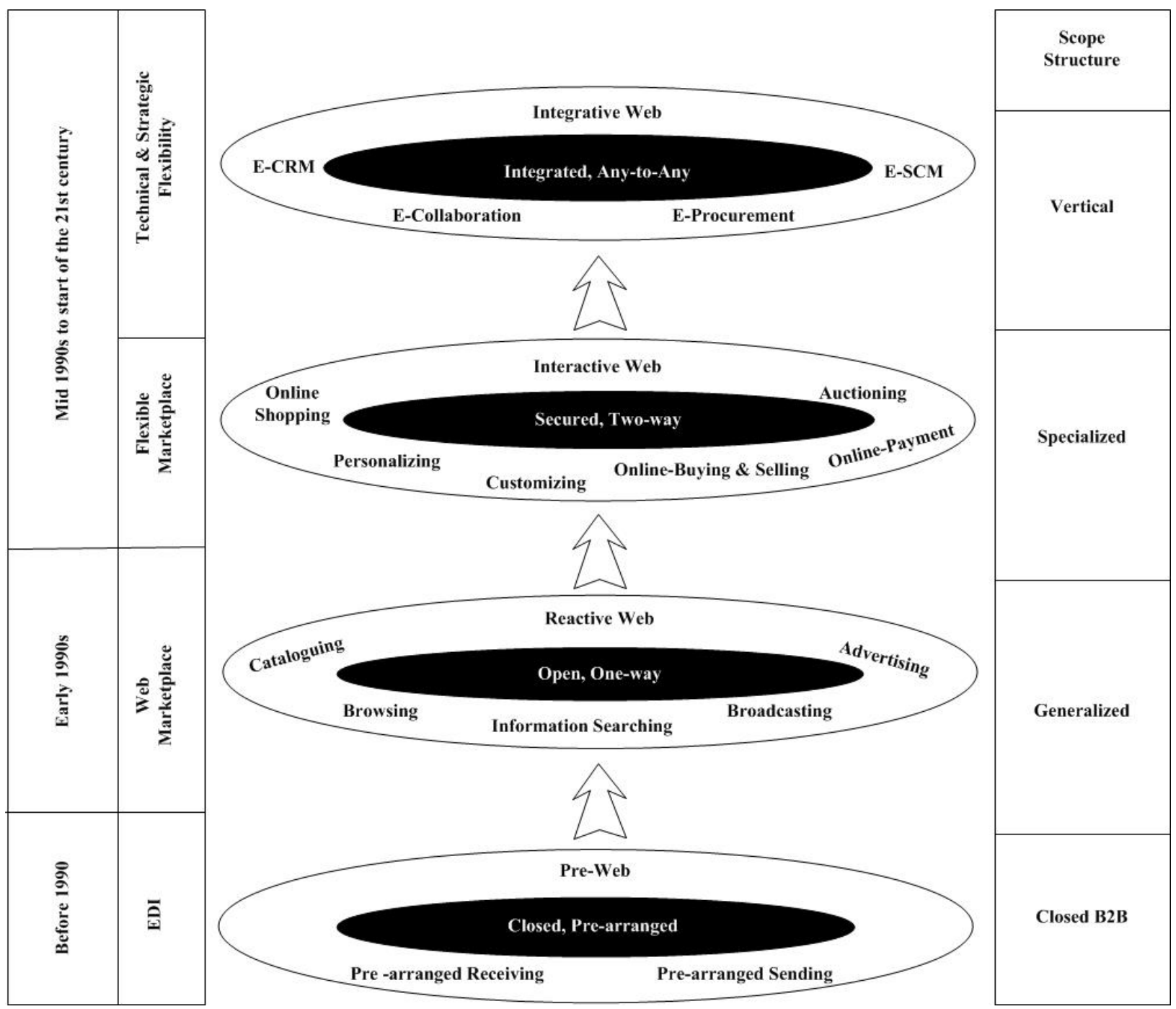

Figure 3: E-commerce web evaluation (adapted from Chu et al. [27])

Before the advent of the World Wide Web, commercial activities were closed: the mechanisms of buying and selling were often rigid. In order for any digital engagement in business activities, the channel of communication had to be negotiated [27]. With the implementation of enterprise resource planning (ERP) or manufacturing resource planning (MRP) systems in the 1980s electronic data interchange (EDI) connections with suppliers were established [84]. Technology at this point did not provide the open interfaces necessary for flexible business connectivity. It was a time of closed, one to one relationship, but the need for development and taking advantage of Internet were observable.

In the early 1990's, with the commercialization of Internet and open computer technology, connectivity becomes affordable to businesses of all sizes. This reactive phase is enabling smaller suppliers to enter the network. Although connected common messaging formats for encoding business activities are not developed and open communication could not be established [27]. Relationships with business partners were designed in indirect procurement [84]. Indirect procurement focused on products and services for maintenance, repair and operations (MRO) and products and services that are neither part of the end product nor resold directly [111]. As e-business activities expand across businesses and industries, e-business processes and online management of business process have evolved to become a separate genre of website. The Internet allowed information to be shared, allowing open access to product and pricing data. With integration of electronic markets and the potential of EPMs to improve effectiveness and efficiency, a considerable number of marketplaces were launched in the dot.com boom, clearly observable at the end of 1990s [66], [82]. In spite of the new communication opportunities, a request for information was typically still oneway and businesses could only react to requests [27]. Furthermore, a lack of secure transmission of confidential information limits the expansion of EPM activities. 
In the mid-1990s, the interactive Web is growing in size and capability of Internet. Many firms are implementing webbased applications and Internet-derived economic change continues to occur. With developing EPM websites, interactive two-way negotiation of buy-sell transactions arises. Personalization and customization were also becoming the main capabilities in online shopping as a result of interactive processes that used new languages [97]. E-shopping, personalized buying, e-selling and new business functions such as ranking, matching authentication and contracting are as result of new EPM activities. Flexible marketplaces evolved from these new Web features.

In late 1990 s to early 2000 , active management became imperative and interoperability began to emerge in some websites. This stage involves the creation of an Internet platform based on XML, which is used to coordinate procurement and distribution flows with suppliers and customers via the network [71]. In essence, it was the creation of a virtual network in which consortiums of companies working in the same field collaborate to increase the efficiency of some particular processes. The other major needs satisfied during this time of evolution were data sharing, online decision support systems, accessibility of databases [18], [27] - an integrative Web. Many tools are available to more fully support EPM processes. They have been developed by key players in e-procurement marketplaces such as Ariba, ComerceOne, Oracle, and SAP. The activities and processes were intertwined online in order to create a website which could be both an e-procurement marketplace and management platform. Facilities provided by such this website improved the collaboration, strategic alliance and business services. An example of this is SCB Co-op, Scotland. The strategic advantage in SCB Co-op is to provide a cost-effective collaborative procurement website. This reduces the need for substantial investments in technology and infrastructure management. Suppliers are more focused on selling their products [101]. In contrast, buyers are offered access to a wide range of goods and services at low prices due to the low cost associated with marketing and distribution channel management for the vendors [101]. Leading Agents in Australia (LAA), portal services such Best of Italy (BOI) and Sofcom.com.au are further examples of this kind of website.

The evolution of the Web has played a large part in the flexible nature of EPM over the review period. Web technologies have been adopted by EPM platforms in order to support businesses of varying size with differing technological capability. The requirements of an infrequent supplier of widgets require less technological integration than that of a key supplier. The variation in technological integration with newer Web technologies provides support for differing collaborations. EPMs have also provided a channel for technology adoption by the vast network of buyers and suppliers in the market - supporting and distributing technologies within (or interfacing into) their platforms.

\subsection{A Synthesis of Flexibility Types Into an EPM Framework}

In this section we synthesize the EPM and flexibility literature into a framework, providing a context from which the systematic literature review can then be undertaken. Table 2 shows the need for flexibility summarized from the literature on EPM.

The framework is conceptual in the sense that it is amalgam of existing work and provides a basis for further analysis. Importantly, the framework and underpinning TOES concerns are grouded in the evolution of e-commerce and EPM evolution over the volatile study period. Examination of flexibility may begin with a specific domain of concern, such as an EPM, and consider how a more flexible design could be achieved. For example, delayed delivery of goods caused by changes in technical platform limitations. The literature provided a considerable number of factors that could be judged to influence the flexibility of EPM. The factors are synthesized in the framework and can be further explored according to levels of frequency of occurrence and influence. At the highest level, certain factors are determined by the organizational aspects in which the marketplace and companies operate. At the next level, certain factors are determined by strategic aspects in which the marketplace operates. A further two aspects are included technical and environmental. 
Table 2: Need for flexibility on EPM domain

\begin{tabular}{|l|l|}
\hline Flexibility is required to & Reference \\
\hline Response to changing market condition, regulations & {$[32]$} \\
& {$[98]$} \\
& {$[102]$} \\
\hline Response to customers and suppliers requirements & {$[14]$} \\
& {$[17]$} \\
\hline Response to changes in technology & {$[108]$} \\
\hline Changes in business strategy & {$[15]$} \\
\hline Changes in business models and processes & {$[38]$} \\
\hline Changes in the level, location and type of resources (e.g. data,, & {$[36]$} \\
storage, applications, services, transactions, bandwidth) & {$[68]$} \\
\hline Changing in industrial relations and coordination (agreements & {$[24]$} \\
and outsourcing arrangements) & {$[30]$} \\
& {$[43]$} \\
& {$[79]$} \\
\hline Management of financial flow & {$[2]$} \\
& {$[46]$} \\
\hline Development or adoption and deployment of products, services, & {$[36]$} \\
systems, logistics, architecture, applications and data & {$[68]$} \\
& {$[103]$} \\
\hline
\end{tabular}

\subsubsection{Flexibility and Technology}

Technological flexibility is the ability to acquire and use hardware and software in a flexible manner. As Vizard [104] reported, in order to build a system for online business, a number of hardware and software applications need to be synchronized. Without this co-ordination companies will be locked into using rigid systems that hamper their evolution, unable to benefit from system upgrades and patches. Nelson et al. [74] define technology flexibility as consisting of structural and process flexibility. Structural flexibility "reflects the ability of the design of a technology to be adapted to changes in the business process and is pro-actively designed into the technology" [73]. Process flexibility is "the ability of people to make changes to the technology using management process that support business process changes" [73].

Within e-procurement online exchanges, flexible technology can bring efficiency by having the same technological platforms, using compatible software able to accommodate the different technologies buyers and sellers use. Chen [25] indicated that technological flexibility was one of the reasons why Citibank's B2B site CitiCommerce did not take off in Asia. An example of technological flexibility in EPM is flexible extranet sites. Technical flexibility in extranet sites is driven by customers requiring an ability to store purchasing contract, pricing and purchasing histories and for suppliers when coping with this growing and changing customer demand. Upton [102]-[103] noted that other aspects may affect the technological flexibility - including the age and scale of the technology on the product and production flexibility. In particular, Upton found that as technology scale increased, flexibility decreased. Alternatively, if the age of technology increases (older equipment or software platforms), the level of product flexibility will likely decrease. However, older technology is able to increase production flexibility because it is easier to cope with the process instabilities resulting from producing [102]-[103]. Vokurka [105] argued the different dimensions of manufacturing flexibility do not equally impact the different aspects of technology.

Technological flexibility can help EPM become more competitive in rapidly changing environments. Technology is not the only factor that needs to be addressed however other element also need to be considered. In support of this assertion, Ozer [78] stated that technology gains importance when other system components functions effectively.

\subsubsection{Flexibility and Organization}

Organizational flexibility is defined as "the ease with which the organization's structures and processes can be changed" [55] p. 583. Volberda [106] state that organizational flexibility can implement a variety of actual and potential procedures in order to increase the control capability of the management and improve the controllability of the organization and environment. 
Organizational flexibility in EPM recognizes reconfiguration and adjustment of operations. It will only be as successful as the flexibility of the workforce and organizational environment allows [33]. Consequently, major challenges for organizations are environmental fluctuations that disturb the organizations equilibrium [80]. One solution is designing operational characteristics and appropriate behavioral aspects within organizations. A key question here is what organizational characteristics and behaviors are important in the realization manufacturing flexibility. Suarez et al. [98] identifies the beneficial effects of several managerial-based policies involving the use of lean management practices, supplier involvement, and utilizing fixed wage scales on new design, volume, and production flexibilities [98], [105]. Organizational aspects studies by Upton [102]-[103] revealed that several relationships are involved in product and production flexibility. He examined the effect of production and product flexibility on managerial aspects and finds that the workforce structure had a negative impact on product flexibility whereas it has positive effects on production flexibility [102]-[103], a possible reason for this is that less experienced operators may be more flexible in their ability to make certain types of changes quickly between products. Once internal operational flexibility is achieved the practitioner needs to look more widely at business environment.

Organizational flexibility can help EPM to anticipate, respond or adapt to changes such as structure, policies, processes, finances and mergers and acquisitions [44], [64], and [67]. Accordingly, careful design and management of EPM is required, in order to increase organizational flexibility and performance.

\subsubsection{Flexibility and Environment}

This section clearly indicates the importance of any system or organization being able to cope with changing circumstances - externally or environmentally generated changes - and in particular changes in market conditions. From an external perspective, it is management capability to influence the environment (or interface to the environment) that enables the firm to be less vulnerable to environmental changes [43], [106]. Vokurka [105] explained the ability or inability of management to predict new events happening in their organizational environments with a resulting unbalance between products and orders. Bourgeois [13] classified environmental flexibility as attributes referring to the diversity in external factors facing an organization or organizational legislations, and the degree of stability or instability in the marketplace in which a firm operates. Aaker et al. [1] defined flexibility as the ability of a firm to cope with instability caused by the environment. As noted by Beckman [9] p. 127, "it is important that your company understand what types of variability it is dealing with, as they each may require different types of flexibility on the part of the organization".

Environmental flexibility (reacting to unpredictable changes in the environment) is closely related to market flexibility, unsurprising as the market operates within an environment. Wernerfelt [109] and Sethi [88] summarized some of the EPM's contextual factors with respect to environmental flexibility as industry (e.g., competitive environment, mergers), globalization of business and changing business.

\subsubsection{Flexibility and Strategy}

Strategic flexibility is "an expedient capability for managing capricious settings, such as those confronted in technology intensive arenas" [39] p. 69. Strategic flexibility typically consists of managerial capabilities in relation to the goals of the organization or the volatility of the environment [1], [43]. This form of flexibility is largely qualitative in nature and can have a major impact on organizational activities [43]. More holistically, strategic flexibility can be considered as the relationship between the business environment, business strategy formulation, and the manufacturing strategy [8]. Strategic flexibility in an organization could be creating a new product and market combination, using market power to deter entry and control competitors, or engaging in political activities to counteract trade regulation [43]. From this perspective, it could also be critical when applying new technologies (including platform or process changes to EPMs being utilized) and renewing products or services [1], [43].

Theoretical relationships between flexibility and strategy have also been of interest [8], [49], [62], [105]. The earliest empirical study examining the link between strategy and manufacturing flexibility by Ettlie and Penner-Hahn [37] investigated product concentration and focus within the manufacturing strategy. Two findings on product and production flexibility were reported. Firstly, they found increased focus the firm's manufacturing strategy resulted in lower production flexibility - as measured by the number of unique parts scheduled for production throughout the year. Second, they found there was no demonstrated effect of strategy on product flexibility [37], [105]. Daniel [31] stated that strategy adopted by an organization impacted on whether it is involved in an e-marketplace and what type of marketplace it chooses to participate with [31].

From the above discussion on flexibility within a strategic context, it can be seen that strategic flexibility is able to critically impact organizational effectiveness. If we ignore flexibility we may create systems that become a barrier or inhibitor of change [43]. 


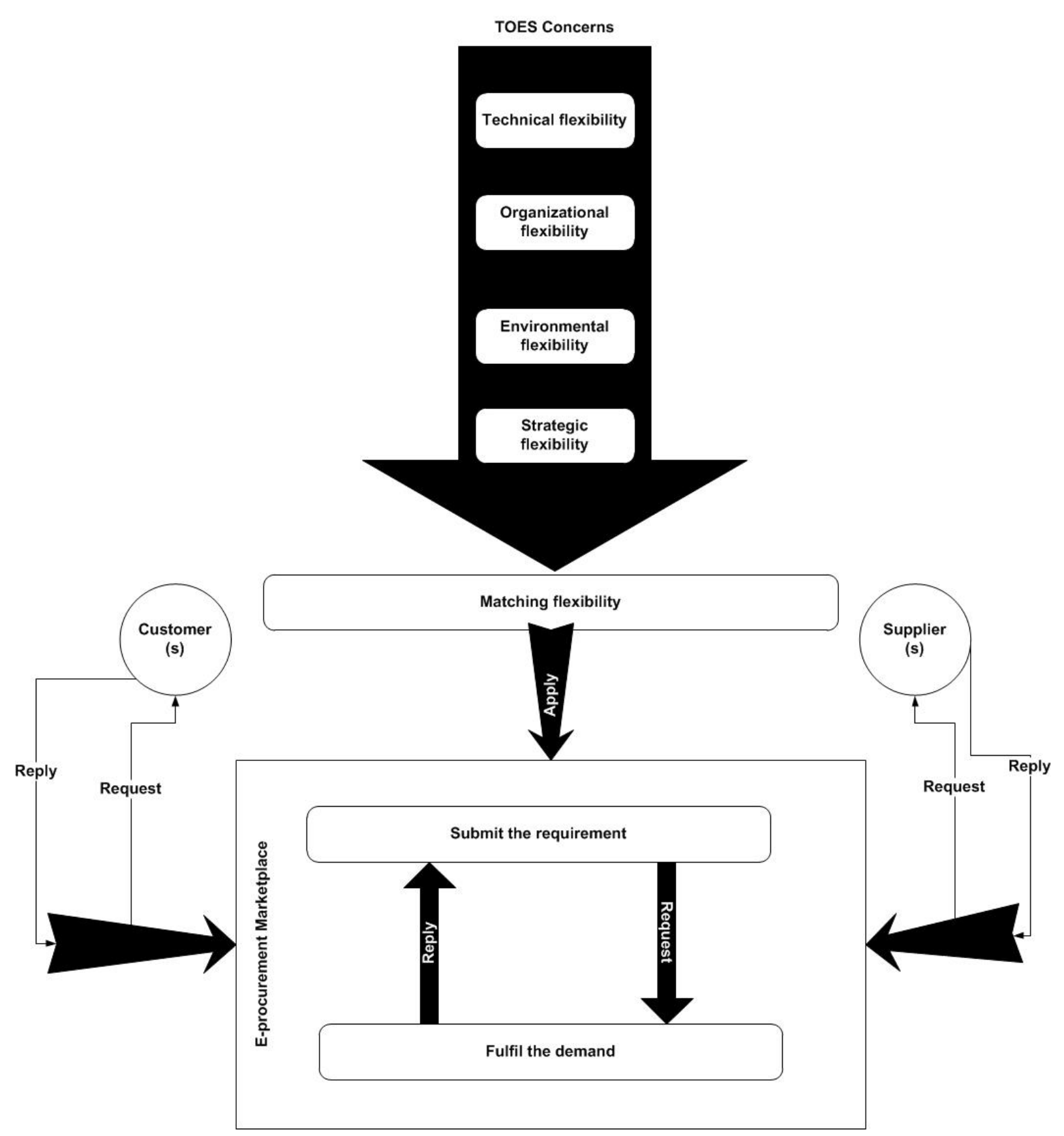

Figure 4: A proposed framework of the flexibility of EPM

\subsubsection{Matching Flexibility}

Matching flexibility represents the use and adoption of flexibility elements (TOES concerns) in the process of matching requests and responses (bids and offers) - including their specification (see figure 4). It is envisaged that each concern will be practically addressed when either designing or choosing an appropriate marketplace or planning its usage.

Fisher et al. (1994) state that accurate response to changes in organizations as well as online procurement increases the matching capability. This has a financial impact on the organizations [42]. Childerhouse et al. [26] develop a route map for supply chain to match customer requirements. They state that in order to avoid costly and ineffective mismatches from strategy to product characteristics, flexible matching should consider as an important perspective. Standing et al. [95] provide a comprehensive review of more general e-marketplace literature from 1997-2008, highlighting the key themes of electronic market theory, systems perspectives, adoption, organization implications and e-commerce issues. They state that further research is required on the e-marketplace selection process to guide firms in matching their requirements to types of e-marketplaces. 


\section{Research Methodology}

This section presents a Systematic Literature Review (SLR) undertaken to investigate EPM evolution over the past decade. Kitchenham [59] describes several reasons of undertaking a systematic review, the most common are to synthesize the available research concerning a treatment or technology, identification of topics for further investigation and formulation of a background in positioning new research activities. In this paper we use SLR to address the need for a longitudinal view in times of great volatility and in order to understand the viability of EPMs with respect to current and future flexibility. We have carried out the SLR using the aforementioned template, and have also taken into account the guidelines given by Biolchini [12] and Kitchenham [59]. The volatility of EPM utilization as the Web continues to develop warrants a systematic analysis of research over the early Web evolution period. The steps undertaken in the systematic literature review method are documented below.

\subsection{The Research Questions}

In order to instigate and guide SLR activities, the research questions have been defined (page 50). RQ1 aims to provide a recent history of EPMs. This is particularly important as it covers the Web era of marketplace innovation. RQ2-4 attempt to uncover elements of and detail about actual EPMs and provide support for the conceptual framework detailed earlier (Figure 4). To address RQ1, a number of journal/conferences were identified that published about EPM each specific year. With respect to RQ2, we examine the characteristics of EPM over the period of study in order to validate the EPM architecture (from a requirements perspective). RQ3 is related to both EPM and flexibility and aims to identify the changing factors that limit EPM. Overcoming these limitations allow for further flexibility. With the final question, RQ4, we identified the changing flexible factors in order to further validate the components of the architecture proposed.

\subsection{The Search Process}

The search strategy undertaken is primarily based on identifying alternative keywords and synonyms for terms used in the research questions (such as EPM and flexibility). This is carried out in order to minimize the effect of differences in terminologies. The search process (Figure 5) is a manual search of appropriate conference proceedings and journals. The journal/conference lists were those suggested by Kitchenham [59] - also deemed appropriate for this review of the coverage of highly cited EPM and flexibility literature. The searching process has two phases. Phase one involves the identification and selection of papers that contain the specific search term. Phase two involves the scanning of paper references and aims to identify further key literature. In the first phase, we search using a number of recognized electronic databases (detailed below). The sources categorized for primary study were those suggested by Kitchenham [59] - also deemed appropriate for this review. The chosen sources contain high quality published research recognized within the E-Business research community.

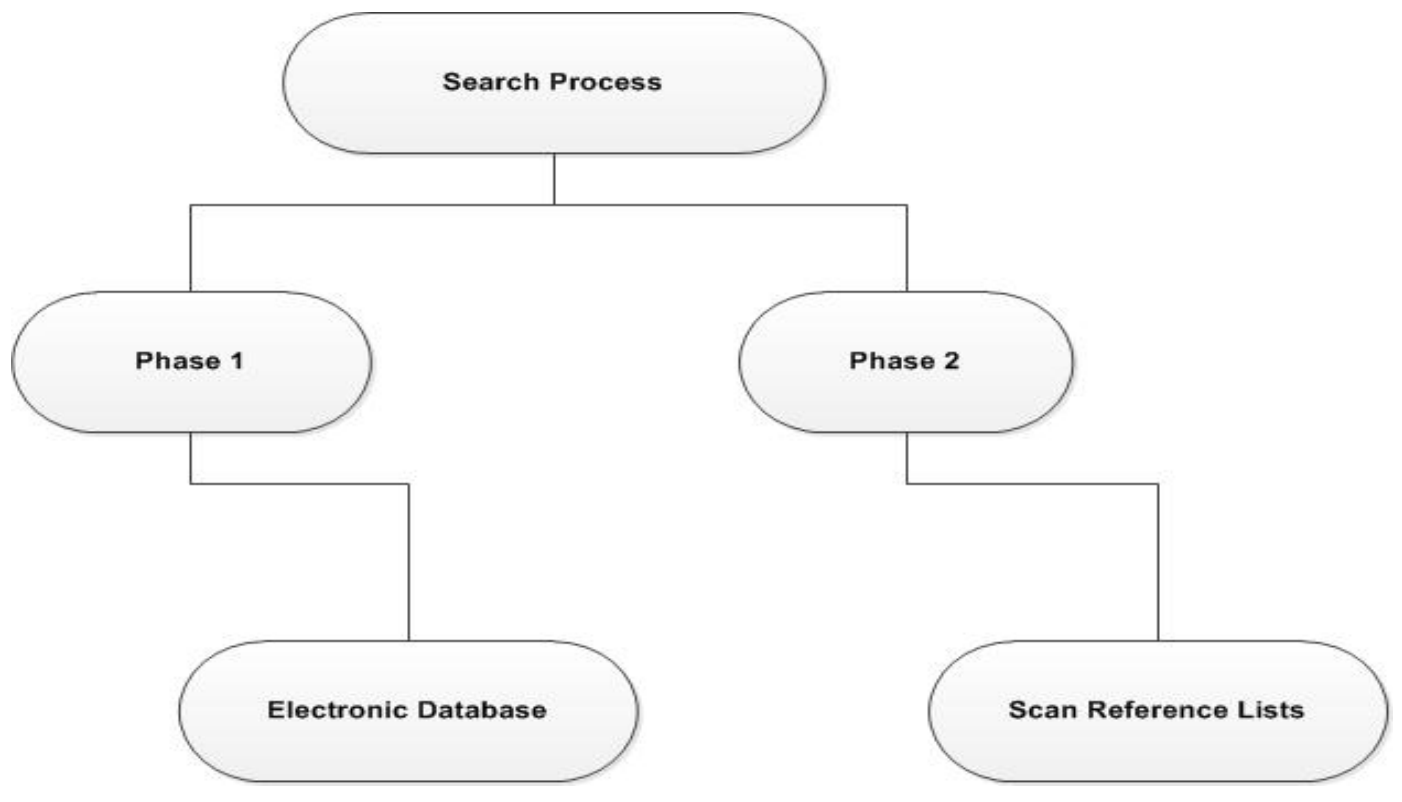

Figure 5: Research process phases (adopted from Afzal (2009) [3])

The selected journal and conferences are shown in the table below (Table 3). Each journal and conference proceeding in phase one is reviewed based on title, abstract and keyword and the papers that addressed eprocurement marketplace were identified as potentially relevant. 
Table 3: Journal/Conference sources

\begin{tabular}{|l|l|}
\hline Source & Website \\
\hline IEEE Xplore computer Society Digital Library & Site 4 \\
\hline ACM Digital Library & Site 1 \\
\hline Citeseer Library & Site 2 \\
\hline ScienceDirect & Site 5 \\
\hline Web of knowledge & Site 6 \\
\hline
\end{tabular}

The second phase is scanning the reference lists of those selected papers and identifies further papers. All searches are based on title, keyword and abstract and took place between July and August 2011. For all the sources, a set of simple search strings are defined. The search results are then combined:

\section{1. (Marketplace AND Electronic Procurement AND Flexibility)}

\section{2. (Marketplace AND E-Procurement AND Flexibility)}

\section{3. (E-Marketplace AND E-procurement AND Flexibility)}

\section{4. (Flexibility AND E-procurement Marketplace)}

Certain synonyms and terms related to the concept of model within the scope of flexible EPM were also taken into account within the search process. Specifically, the term diagram, view and concern have used as synonyms for model. The information retrieved through this search string was used as a guide for the development and validation of the major search terms [57]. The final list of sources, the number of publications found for each resource and the number of duplicate papers are listed in Table 5. The scoping of the study followed Kitchenham et al. [59], [60] and identified an initial list of papers. These were gradually updated during the scoping study. Some papers that were already known to be relevant were used to check the validity of the search terms [60].

Table 4: Data sources and search strategy

\begin{tabular}{|l|l|l|l|l|}
\hline Resource Total & Results found & $\begin{array}{l}\text { Duplicated Initial selection } \\
\text { papers }\end{array}$ & Final selection \\
\hline IEEE Xplore & 104 & 82 & 44 & 2 \\
\hline ACM Digital Library & 86 & 85 & 56 & 5 \\
\hline Citeseer Library & 21 & 21 & 6 & 0 \\
\hline ScienceDirect & 478 & 407 & 276 & 7 \\
\hline ISI web of science & 219 & 156 & 111 & 8 \\
\hline Total & 908 & 751 & 493 & 22 \\
\hline
\end{tabular}

The first phase of research resulted in a total of 908 candidate papers being identified. After eliminating duplicates in more than one electronic database, we were left with 751 papers. Table 4 shows the distribution of papers before duplicate removal among different sources. The corpus of papers initially found and finally utilized are similar to both Afzal et al. [3]- 35 selected from 501 - and Kitchenham et al. [60] - selected 19 from 2,506.

The exclusion was carried out using a filtering approach (Figure 6). To begin with, initial analysis by the researchers excluded 258 references out of all unique publications using title and abstract. These were clearly out of scope for this study and did not relate to the research questions. The remaining 493 references were subject to detailed exclusion criteria, involving two researchers. First, each researcher applied the exclusion criteria independently. Out of 493 references, the two researchers were in agreement on 295 references to exclude, 13 to include and 146 required a meeting to reach consensus. In meetings, researchers tried to convince others; otherwise a third party was asked to analyze the paper and a majority decision was taken. This application of detailed exclusion criteria resulted in 53 remaining references, which were further filtered out by reading full-text. A final figure of 20 primary studies was reached after excluding similar studies that were published in different venues. The 20 primary studies were supplemented with 2 further papers from phase two of the search strategy (Figure 6). The few resulting papers from Phase two indicates the effectiveness of the earlier search process. 


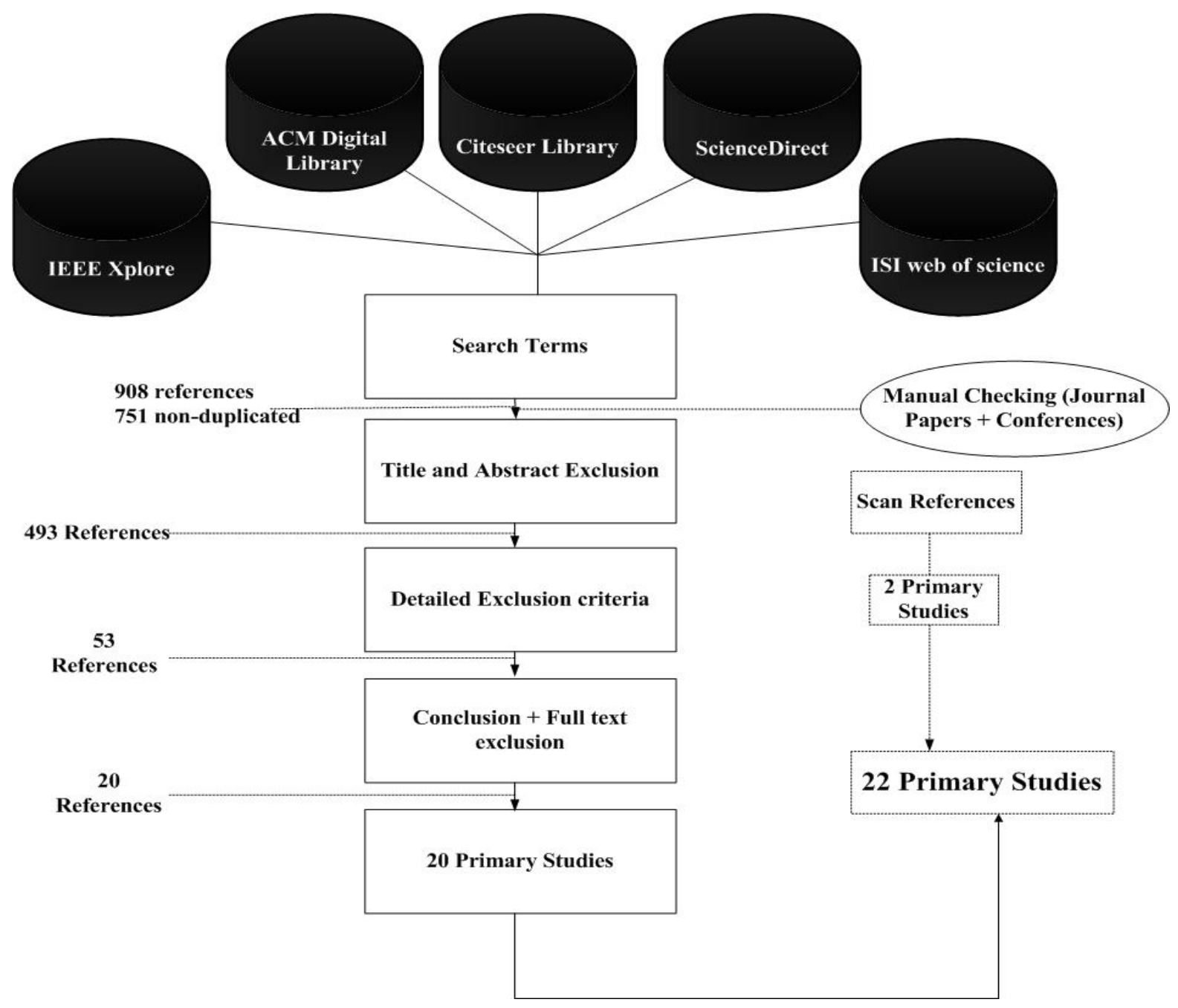

Figure 6: Multi-step filtering of studies and final number of primary studies (adapted from Afzal et al. [3])

\subsection{Inclusion and Exclusion Criteria}

Inclusion criteria attempt to find the most appropriate papers that support the research questions. Data inclusion criteria determine which journals or conferences (found by the search terms) are used for data extraction. A selection process that uses candidate search terms has shown that, in many cases, interpreting the paper title provides adequate support for inclusion in the study. Unsurprisingly, when the terms of the query are commonly used in literature (as is the case with this study), many papers not related to the subject of this SLR are found. When the title is not sufficient to determine whether the paper should be included, the abstract is then read and, if necessary, the introduction and finally the whole paper.The criteria used to determine whether the literature found by the search term should be included are studies that describe: market-based e-procurement; the flexibility factors in the selection process of procurement marketplace; the relationship between flexibility and e-procurement marketplace and motivations in flexible market-based e-procurement.

The intention is that this SLR should concentrate upon identifying flexibility concepts (and taxonomy) for flexible market-based e-procurement. Since (1) it is difficult to obtain access to all the flexibility aspects within a single paper and (2) markets change continuously, it is important to extract papers that allow analysis of evolution. Again, duplicate reports of the same study are also excluded in the SLR: Only the most complete versions of the research are included. Studies were excluded if not directly relevant to the research questions or do not describe flexibility with respect to market-based e-procurement or e-procurement processes.

\subsection{Threats to the Validity of this SLR (Quality Assessment)}

Each paper was evaluated using the Database of Abstracts of Reviews of Effects (DARE) criteria [20]. DARE was produced by York University, Centre for Reviews and Dissemination (CDR). The criteria are based on four quality assessment $(\mathrm{QA})$ questions: 
QA1. Are the review's inclusion and exclusion criteria described and appropriate?

QA2. Is the literature search likely to have covered all relevant studies?

QA3. Is it clear the de-motivated factors in e-procurement marketplace to be more flexible?

QA4. Is it clear what the architectural components of Flexible e-procurement marketplace are?

The questions were scored as follows: QA1: $Y$ (yes), the inclusion criteria are explicitly defined in the study, P (Partly), the inclusion criteria are implicit; $N$ (no), and the inclusion criteria are not defined and cannot be readily inferred. QA2: $Y$, the authors have either searched 4 or more digital libraries and included additional search strategies or identified and referenced all journals addressing the topic of interest; $P$, the authors have searched 3 or 4 digital libraries with no extra search strategies, or searched a defined but restricted set of journals and conference proceedings; $\mathrm{N}$, the authors have search up to 2 digital libraries or an extremely restricted set of journals. QA3: Y, the authors have explicitly defined quality criteria and extracted them from each primary study; $P$, the research question involves quality issues that are addressed by the study; $\mathrm{N}$ no explicit quality assessment of individual primary studies has been attempted. QA4: $Y$ Information is presented about each study; $P$ only summary information about primary studies is presented; $\mathrm{N}$ the results of the individual primary studies are not specified. The scoring procedure was $Y=1, P=0.5, N=0$, or Unknown (i.e. the information is not specified). Kitchenham [59]-[60] coordinated the quality evaluation extraction process. Kitchenham [59]-[60] assessed every paper, and allocated 4 papers to each of the other authors of this study to assess independently. When there was a disagreement, we discussed the issues until we reached agreement. When a question was scored as unknown we e-mailed the authors of the paper and asked them to provide the relevant information and the question re-scored appropriately.

\subsection{Data Extraction}

A data extraction form adapted from Biolchini et al. [12] is filled in for each selected work (Table 4). Data extracted from each study includes a full reference, the author(s), their institution and the country where it is situated and the number of citations.

\subsection{Data Analysis}

Data was tabulated (Table 5) to show: (1) the number of journal/conference papers that published about EPM per year and their sources (Addressing RQ1), (2) whether or not the journal/conference papers referenced the characteristics of EPM (addressing RQ2), (3) whether or not those journal/conference papers referenced flexibility aspects (Addressing RQ3). The architectural components of flexible EPM (Addressing RQ4) are discussed later.

\section{Discussion}

In this section we describe the evaluation of the assessed literature in relation to the research questions. Each of the 22 primary studies are allocated to specific flexibility types, previously identified: Environmental, technical, strategic and organizational. The number of primary studies covering each flexibility type is: 7 (Environmental), 12 (Technical), 12 (Strategic) and 4 (Organizational). Additional detail of the distribution of primary studies within each flexibility type is shown in Table 5. 
Table 5: Distribution of primary studies per flexibility aspects

\begin{tabular}{|c|c|c|c|}
\hline $\begin{array}{l}\text { Flexibility } \\
\text { Types }\end{array}$ & Author(s) & Year & References \\
\hline Environmental & $\begin{array}{l}\text { Das, TK } \\
\text { Byrd, T.A. } \\
\text { Legorreta, L. } \\
\text { Gosain, S. } \\
\text { Fredericks, E. } \\
\text { Fitzgerald, G. } \\
\text { Merschmann, U. }\end{array}$ & $\begin{array}{l}1995 \\
2000 \\
2001 \\
2004 \\
2005 \\
2009 \\
2010\end{array}$ & $\begin{array}{l}73 \\
321 \\
7 \\
141 \\
26 \\
4 \\
1\end{array}$ \\
\hline Technical & $\begin{array}{l}\text { Byrd, T.A. } \\
\text { Legorreta, L. } \\
\text { Ozer, M. } \\
\text { Shi, D. } \\
\text { Skjott-Larsen, T. } \\
\text { Pujawan, I.N. } \\
\text { Giunipero, L.C. } \\
\text { Avittathur, B. } \\
\text { Fitzgerald, G. } \\
\text { Hallgren, M. } \\
\text { Tachizawa, E.M. } \\
\text { Gosling, J. }\end{array}$ & $\begin{array}{l}2000 \\
2001 \\
2002 \\
2003 \\
2003 \\
2004 \\
2005 \\
2007 \\
2009 \\
2009 \\
2010 \\
2010\end{array}$ & $\begin{array}{l}321 \\
7 \\
9 \\
44 \\
88 \\
51 \\
32 \\
22 \\
4 \\
18 \\
2 \\
4\end{array}$ \\
\hline Strategic & $\begin{array}{l}\text { Das, TK } \\
\text { Grewal, R. } \\
\text { Duclos, L.K. } \\
\text { Johnson, J.L. } \\
\text { Shi, D. } \\
\text { Pateli, A.G. } \\
\text { Pujawan, I.N. } \\
\text { Fredericks, E. } \\
\text { Giunipero, L.C. } \\
\text { Hallgren, M. } \\
\text { Fitzgerald, G. } \\
\text { Tachizawa, E.M. }\end{array}$ & $\begin{array}{l}1995 \\
2001 \\
2003 \\
2003 \\
2003 \\
2003 \\
2004 \\
2005 \\
2005 \\
2009 \\
2009 \\
2010\end{array}$ & $\begin{array}{l}73 \\
319 \\
123 \\
87 \\
44 \\
94 \\
51 \\
26 \\
32 \\
18 \\
4 \\
2\end{array}$ \\
\hline Organizational & $\begin{array}{l}\text { Das, TK } \\
\text { Duclos, L.K. } \\
\text { Fredericks, E. } \\
\text { Swafford, P.M. }\end{array}$ & $\begin{array}{l}1995 \\
2003 \\
2005 \\
2008\end{array}$ & $\begin{array}{l}73 \\
123 \\
26 \\
40\end{array}$ \\
\hline
\end{tabular}

In order to explore the evolution of EPM a number of axes require analysis. Understanding the temporal aspects of specific flexibility types and within specific domains is also required. Figure 7 shows this year-wise distribution of primary studies within each flexibility aspects as well as the frequency of application within different domains. Each bubble depicts the underling literature and contains the name of the author(s) and the number of citation of the contribution(s). It is evident from the chart that the manufacturing and market domain are the most widely studied with respect to flexibility. In the left quadrant of Figure 7, each bubble represents the author name (s) of primary studies within each flexibility aspects in respective years from 1995-2010. The pharmaceutical domain has had little analysis over the past decade; and finance has not had full coverage of all flexibility aspects. Flexibility aspects have also gained popularity in the research community at different points in time. Technical flexibility has been recently popular as opposed to strategic flexibility that peaked in 2003. Organizational flexibility appears to have had regular coverage between 2003 and 2008, with little coverage in the recent past. 


\section{Flexibility Aspects}

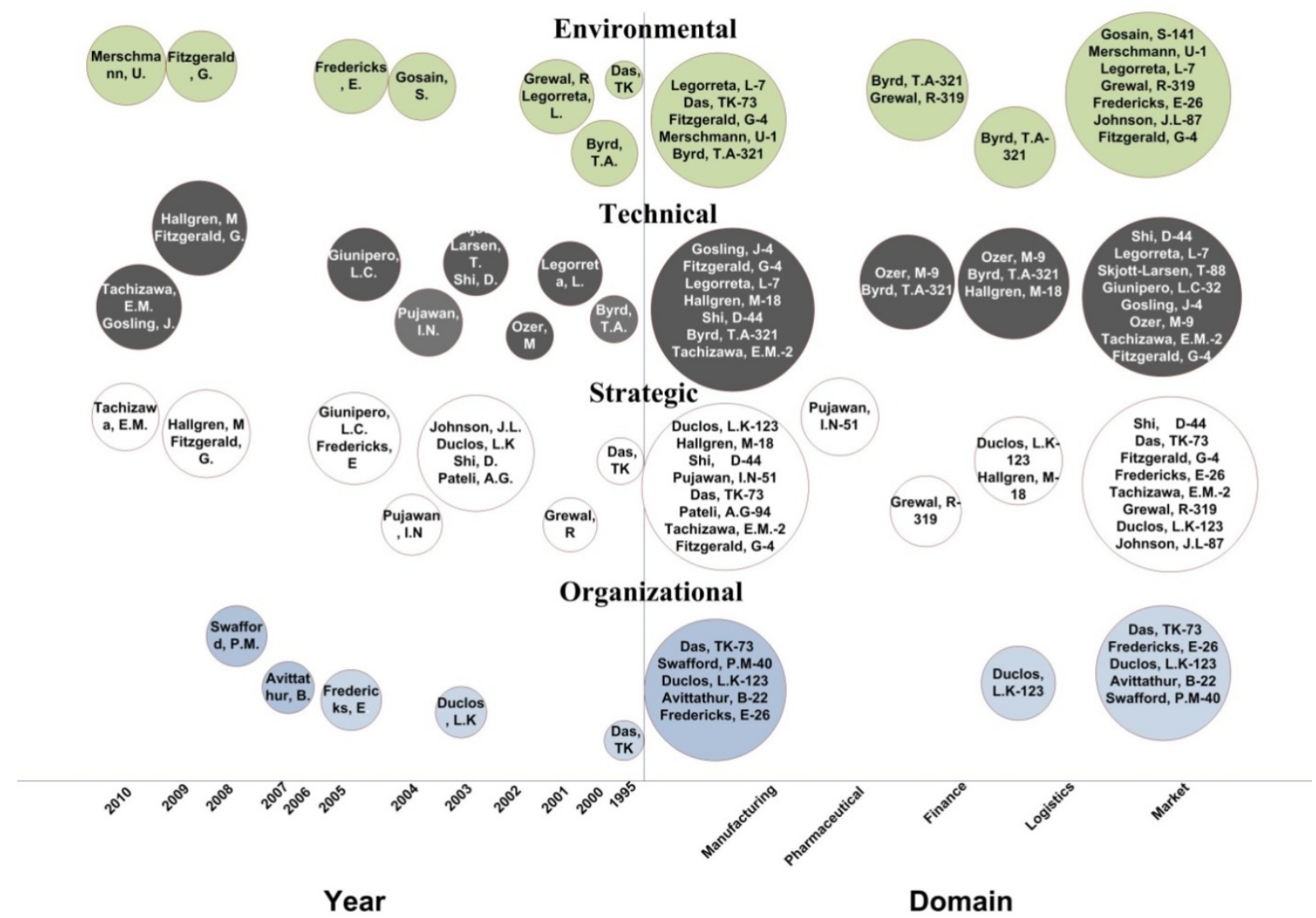

Figure 7: Distribution of flexibility research since 1995

\subsection{Domain Impact}

Each bubble represents the author name(s) of primary studies within each flexibility aspects in respective years from 1995-2010. As the distribution of flexibility concerns shows in figure 7, the number of authors working on flexibility has decreased somewhat. From 1995 to 2001, the majority of the published papers are covering technical and environmental flexibility. This gradual increase from 2002 to 2005 has typically focused on strategic and technical flexibility. From 2006 to 2010, only one of the papers published covers three out of four flexibility aspects. It is apparent that more research is required covering flexibility across all the criteria's.

Research on e-procurement in manufacturing domain is more mature than that in information systems. To explain, Harrigan et al. [54] p. 2 have made a general observation and stated that from a strategic perspective procurement can encompass "the entire operation including a company's requisitioning, transportation, warehousing, and inbound receiving processes", where the dominant goal is process efficiency. In a recent research, Fitzgerald et al. [43] considered all aspects of flexibility in manufacturing and marketplaces. They found that manufacturers are more likely to require flexibility in their strategic, environmental and technical activities.

The pharmaceutical domain has had little analysis over the past decade. Buyers and suppliers must work together toward standardization including agreeing on a universal product numbering system [72]. There is only one related work on flexibility in e-procurement. This is surprising as it has been clear to the authors that flexible e-procurement is an important strategic goal for pharmaceuticals and their networks.

Within the finance domain it is often difficult to explore procurement due in part to complexity and security concern. Complexity results from the synthetic nature of services (and products) offered; and the variation in supporting products and services. In addition, e-procurement literature indicates that many corporate-level executives hold a traditional view of procurement and do not fully recognize its impact on all areas of financial performance. Many professionals do not understand the language of finance, and thus fail to articulate the real value of their solutions at the corporate level [83]. In figure 7 there are only three papers published in financial domain, mainly around technical and environmental concerns. 
It is a common notion that logistics involves the movement of physical goods from one location to another. Cavinato [19] has defined logistics as the management of all inbound and outbound materials, parts, supplies and finished goods. Logistics consists of the integrated management of purchasing transportation and storage on a functional basis. Logistic e-procurement is more popular, with authors mainly focusing on the flow of information among multiple players involved in the delivery process.

The value-creating potential of e-procurement has significant implications for the industrial marketer. Industrial marketers need to understand the value-creating benefits that are driving their potential customers and suppliers to aggressively exploit the advantages of the Internet in adopting e-procurement strategies. The move away from the transaction focus of more traditional purchasing has profound implications for the industrial marketer [83] - benefiting from competitiveness gained from the Internet. Finally, the pharmaceutical domain has had little analysis over the past decade; and finance has not had full coverage of all flexibility aspects. Flexibility aspects have also gained popularity in the research community at different points in time. Technical flexibility has had recent popularity, whereas strategic flexibility that peaked in 2003. Organizational flexibility appears to have had regular coverage between 2003 and 2008, with little coverage in the recent past. It is clear that more research is required in these under-analyzed domains, unpicking the differing aspects of flexibility.

\section{Conclusion}

In this systematic review, we have synthesized and analyzed concepts, empirical findings, and gaps in literature with the purpose of understanding the viability and likely evolution of EPMs with respect to current and future flexibility requirements. The study uses a broad, multi-dimensional perspective of EPM and flexibility.

A conceptual EPM architecture is presented early in the paper in order to provide context from which the review can be presented. The architecture is derived from literature with the purpose of better understanding the flexibility elements of EPMs and their importance over time with e-commernce and EPM evolution over the study period directing framework design. The framework consists of four interrelated elements: (a) technical, (b) organisational, (c) environmental and (d) strategic (TOES) concerns. Unsurprisingly, the TOES flexibility types are central to this architecture and require consideration when defining buyer-supplier interaction. At the same time, firms must also realize that competition is not derived from organization-to-organization pressures, but also the EPM to EPM landscape. Having such a strategic focus will help businesses avoid costly and ineffective mismatches between customer requirements to product characteristics.

Meanwhile, the evolution of Web from individual organization flexibility to cross-organization flexibility has resulted in a requirement that the entire EPM platform be flexible. At issue is what specific EPM flexibility components require consideration? Much has been written on the components of strategic manufacturing flexibility. A brief summary of that literature has been provided. Our finding shows that little consideration is typically given to the organisational and environmental aspects of flexibility in current platforms however. This systematic review itself investigated flexibility concerns around EPM. The 22 primary studies are distributed across Technical (12 papers), Environmental (7 papers), Organizational (4 papers) and Strategic (12 papers) flexibility.

Considering our framework, the evolving Web and our profile of EPM flexibility research, it can be argued that there is a strong relationship between our framework and the evolution of e-commerce activities. The evolution of the Web has played a large part in the flexible nature of EPMs over the review period. Web technologies have been adopted by EPM platforms in order to support businesses of varying size with differing technological capability. The requirements of an infrequent supplier of widgets require less technological integration than that of a key supplier. The variation in technological integration with newer Web technologies provides support for differing collaborations. EPMs have also provided a channel for technology adoption by the vast network of buyers and supplier in the market - supporting and distributing technologies within (or interfacing into) their platforms. This research suggests that, while these flexibility types are important in the current business environment, managers may also benefit from integrating dynamic procurement architectures and environments (e.g., with a number of back-end systems and processes).

\section{Websites List}

Site 1: ACM Digital Library

http://portal.acm.org/

Site 2: CiteSeerX

http://citeseerx.ist.psu.edu/

Site 3: EmarketServices

www.emarketservices.com 
Site 4: IEEE Xplore

http://ieeexplore.ieee.org/

Site 5: Science Direct

http://www.sciencedirect.com/

Site 6: Web of Knowledge

http://portal.isiknowledge.com/

\section{References}

[1] D. A. Aaker and B. Mascarenhas, The need for strategic flexibility, Journal of Business Strategy, vol. 5, no. 2, pp. 74-82, 1984.

[2] M. A. Abernethy and A. M. Lillis, The impact of manufacturing flexibility on management control system design, Accounting, Organizations and Society, vol. 20, no. 4, pp. 241-258, 1995.

[3] W. Afzal, R. Torkar, and R. Feldt, A systematic review of search-based testing for non-functional system properties, Information and Software Technology, vol. 51, no. 6, pp. 957-976, 2009.

[4] E. A. Ageshin, E-procurement at work: A case study, Production and Inventory Management Journal, vol. 42, no. 1, pp. 48-53, 2001.

[5] G. C. Ash and J. M. Burn, Assessing the benefits from e-business transformation through effective enterprise management, European Journal of Information Systems, vol. 12, no. 4, pp. 297-308, 2003.

[6] J. Y. Bakos, A strategic analysis of electronic marketplaces, Management Information Systems Quarterly, vol. 15, no. 3, pp. 295-310, 1991.

[7] M. Barad and D. Even Sapir, Flexibility in logistic systems-modeling and performance evaluation, International Journal of Production Economics, vol. 85, no. 2, pp. 155-170, 2003.

[8] R. Beach, A. Muhlemann, D. Price, A. Paterson, and J. Sharp, A review of manufacturing flexibility, European Journal of Operational Research, vol. 122, no. 1, pp. 41-57, 2000.

[9] S. L. Beckman, Manufacturing flexibility: The next source of competitive advantage, in Strategic Manufacturing: Dynamic New Directions for the 1990s (P. E. Moody, Ed.). Homewood, Illinois: Richard D. Irwin, Inc, 1990, pp. 107-132.

[10] M. Behrsin, G. Mason, and T. Sharpe, Reshaping IT for Business Flexibility. Boston: McGraw-Hill, Inc., 1994.

[11] M. Bichler and J. Kalagnanam, Configurable offers and winner determination in multi-attribute auctions, European Journal of Operational Research, vol. 160, no. 2, pp. 380-394, 2005.

[12] J. Biolchini, P. G. Mian, A. C. Natali, and G. H. Travassos, Systematic review in software engineering, System Engineering and Computer Science Department COPPE/UFRJ, Rio de Janeiro, Brazil, Technical Report ES $679 / 05,2005$

[13] L. J. Bourgeois, Strategy and environment: A conceptual integration, The Academy of Management Review, vol. 5, no. 1, pp. 25-39, 1980.

[14] M. Broadbent and P. Weill, Management by maxim: How business and IT managers can create IT infrastructures, Sloan Management Review, vol. 38, no. 3, pp. 77-92, 1997.

[15] M. Broadbent, P. Weill, and B. Neo, Strategic context and patterns of IT infrastructure capability, The Journal of Strategic Information Systems, vol. 8, no. 2, pp. 157-187, 1999.

[16] J. Browne, D. Dubois, K. Rathmill, S. P. Sethi, and K. E. Stecke, Classification of flexible manufacturing systems, The FMS magazine, vol. 2, no. 2, pp. 114-117, 1984.

[17] A. T. Byrd and D. E. Turner, Measuring the flexibility of information technology infrastructure: Exploratory analysis of a construct, Journal of Management Information Systems, vol. 17, no. 1, pp. 167-208, 2000.

[18] C. Carlsson and E. Turban, Introduction: DSS: Directions for the next decade, Decision Support Systems, vol. 33, no. 2, pp. 105-110, 2002.

[19] J. Cavinato, The traffic service corporation. Washington, DC: The Traffic Service Corporation, 1982.

[20] Centre for Reviews and Dissemination. (2013, June) What are the criteria for the inclusion of reviews on DARE?. [Online]. Available: http://www.crd.york.ac.uk/NIHR CRDWEB/AboutDare.asp.

[21] D. Chaffey, E-Business and E-Commerce Management: Strategy, Implementation, and Practice. New Jersey: Financial Times/Prentice Hall, 2006.

[22] S. Chambers, Flexibility in the Context of Manufacturing Strategy, Manufacturing Strategy: Process and Content. London: Chapman \& Hall, 1992.

[23] H. H. Chang and K. H. Wong, Adoption of e-procurement and participation of e-marketplace on firm performance: Trust as a moderator, Information \& Management, vol. 47, no. 5-6, pp. 262-270, 2010.

[24] S. C. Chang, C. L. Yang, H. C. Cheng, and C. Sheu, Manufacturing flexibility and business strategy: An empirical study of small and medium sized firms, International Journal of Productions Economics, vol. 83, no. 1, pp. 13-26, 2003.

[25] M. K. Chen and Y. C. Chung, The survey of the collaborative commerce implementation in Taiwan, International Journal of Electronic Business, vol. 7, no. 1, pp. 45-56, 2009.

[26] P. Childerhouse and D. Towill, Engineering supply chains to match customer requirements, Logistics Information Management, vol. 13, no. 6, pp. 337-346, 2000.

[27] S. C. Chu, L. C. Leung, Y. V. Hui, and W. Cheung, Evolution of e-commerce web sites: A conceptual framework and a longitudinal study, Information \& Management, vol. 44, no. 2, pp. 154-164, 2007. 
[28] C. H. Chung and I. J. Chen, Managing Flexibility of Flexible Manufacturing Systems for Competitive Edge. Berlin: Springer-Verlag, 1990.

[29] Q. Dai and R. J. Kauffman, Business models for internet-based e-procurement systems and B2B electronic markets: An exploratory assessment, in Proceedings of the $34^{\text {th }}$ Annual Hawaii International Conference, Hawaii, USA, 2001, pp. 9-10.

[30] G. Dangayach and S. Deshmukh, Manufacturing strategy: Literature review and some issues, International Journal of Operations \& Production Management, vol. 21, no. 7, pp. 884-932, 2001.

[31] E. Daniel, J. Hoxmeier, A. White, and A. Smart, A framework for the sustainability of e-marketplaces, Business Process Management Journal, vol. 10, no. 3, pp. 277-289, 2004.

[32] T. Das and B. Elango, Managing strategic flexibility: Key to effective performance, Journal of General Management, vol. 20, no. 3, pp. 60-60, 1995.

[33] L. K. Duclos, R. J. Vokurka, and R. R. Lummus, A conceptual model of supply chain flexibility, Industrial Management \& Data Systems, vol. 103, no. 6, pp. 446-456, 2003.

[34] N. B. Duncan, Capturing flexibility of information technology infrastructure: A study of resource characteristics and their measure, Journal of Management Information Systems, vol. 12, no. 2, pp. 37-57, 1995.

[35] R. Eid, M. Trueman, and A. M. Ahmed, A cross-industry review of B2B critical success factors, Internet Research, vol. 12, no. 2, pp. 110-123, 2002.

[36] C. S. Englehardt and P. R. Simmons, Organizational flexibility for a changing world, Leadership \& Organization Development Journal, vol. 23, no. 3, pp. 113-121, 2002.

[37] J. E. Ettlie and J. D. Penner-Hahn, Flexibility ratios and manufacturing strategy, Management Science, vol. 40, no. 11, pp. 1444-1454, 1994.

[38] B. Evans, The need for agility, InformationWeek, vol. 903, no. 1, pp. 80-82, 2002.

[39] J. S. Evans, Strategic flexibility for high technology manoeuvres: A conceptual framework, Journal of Management Studies, vol. 28, no. 1, pp. 69-89, 1991.

[40] A. M. Fairchild, P. O'reilly, P. Finnegan, and P. M. Ribbers, Multi-criteria markets: An exploratory study of market process design, Electronic Markets, vol. 17, no. 4, pp. 286-297, 2007.

[41] A. Fiegenbaum and A. Karnani, Output flexibility-a competitive advantage for small firms, Strategic Management Journal, vol. 12, no. 2, pp. 101-114, 1991.

[42] M. L. Fisher, J. H. Hammond, W. R. Obermeyer, and A. Raman. (1994, May) Making supply meet demand in an uncertain world. Harvard Business Review. [Online]. Available: http://hbr.org/1994/05/making-supply-meetdemand-in-an-uncertain-world/ar/7.

[43] G. Fitzgerald and F. A. Siddiqui, Business process reengineering and flexibility: A case for unification, International Journal of Flexible Manufacturing Systems, vol. 14, no. 1, pp. 73-86, 2002.

[44] G. Fitzgerald, Achieving flexible information systems: The case for improved analysis, Journal of Information Technology, vol. 5, no. 1, pp. 5-11, 1990.

[45] G. Fitzgerald, M. Barad, A. Papazafeiropoulou, and G. Alaa, A framework for analyzing flexibility of generic objects, International Journal of Productions Economics, vol. 122, no. 1, pp. 329-339, 2009.

[46] A. Gamba and A. Triantis, The value of financial flexibility, The Journal of Finance, vol. 63, no. 5, pp. 22632296, 2008.

[47] A. C. Garavelli, Flexibility configurations for the supply chain management, International Journal of Production Economics, vol. 85, no. 2, pp. 141-153 2003.

[48] J. Gebauer and A. Scharl. (1999, December) Between flexibility and automation: An evaluation of web technology from a business process perspective. Journal of Computer-Mediated Communication. [Online]. vol. 5, no. 2. Available: http://jcmc.indiana.edu/vol5/issue2/gebauer.html.

[49] D. Gerwin, Manufacturing flexibility: A strategic perspective, Management Science, vol. 39, no. 4, pp. 395-410, 1993.

[50] M. Grieger, Electronic marketplaces: A literature review and a call for supply chain management research, European Journal of Operational Research, vol. 144, no. 2, pp. 280-294 2003.

[51] X. De. Groote, The flexibility of production processes: A general framework, Management Science, vol. 40, no. 7, pp. 933-945, 1994.

[52] D. Gupta, On measurement and valuation of manufacturing flexibility, International Journal of Production Research, vol. 31, no. 12, pp. 2947-2958, 1993.

[53] Y. P. Gupta and T. M. Somers, Business strategy, manufacturing flexibility, and organizational performance relationships: A path analysis approach, Production and Operations Management, vol. 5, no. 3, pp. 204-233, 1996.

[54] P. O. Harrigan, M. M. Boyd, E. Ramsey, P. Ibbotson, and M. Bright, The development of e-procurement within the ICT manufacturing industry in ireland, Management Decision, vol. 46, no. 3, pp. 481-500, 2008.

[55] G. P. Huber and R. R. McDaniel, The decision-making paradigm of organizational design, Management Science, vol. 32, no. 5, pp. 572-589, 1986.

[56] S. Jap. (2000, November) Going, going, gone. Harvard Business Review. [Online]. vol. 78, no. 6. Available: http://hbr.org/2000/11/going-going-gone/ar/1.

[57] S. U. Khan, M. Niazi, and R. Ahmad, Factors influencing clients in the selection of offshore software outsourcing vendors: An exploratory study using a systematic literature review, Journal of Systems and Software, vol. 84, no. 4, pp. 686-699, 2011.

[58] C. Kim, Issues on manufacturing flexibility, Integrated Manufacturing Systems, vol. 2, no. 2, pp. 4-7, 1993.

[59] B. Kitchenham and S. Charters, Guidelines for performing systematic literature reviews in software engineering, Engineering, London, United Kingdom, Technical Report, EBSE 2007-001, 2007, vol. 2. 
[60] B. Kitchenham, O. Pearl Brereton, D. Budgen, M. Turner, J. Bailey, and S. Linkman, Systematic literature reviews in software engineering-A systematic literature review, Information and Software Technology, vol. 51, no. 1, pp. 7-15, 2009.

[61] L. L. Koste and M. K. Malhotra, A theoretical framework for analyzing the dimensions of manufacturing flexibility, Journal of Operations Management, vol. 18, no. 1, pp. 75-93, 1999.

[62] V. Kumar, K. A. Fantazy, U. Kumar, and T. A. Boyle, Implementation and management framework for supply chain flexibility, Journal of Enterprise Information Management, vol. 19, no. 3, pp. 303-319, 2006.

[63] A. Lancastre and L. F. Lages, The relationship between buyer and a B2B e-marketplace: Cooperation determinants in an electronic market context, Industrial Marketing Management, vol. 35, no. 6, pp. 774-789 2006.

[64] F. Land, Adapting to changing user requirements, Information \& Management, vol. 5, no. 2, pp. 59-75, 1982.

[65] S. Lee and S. Hershberger, A simple rule for generating equivalent models in covariance structure modeling, Multivariate Behavioral Research, vol. 25, no. 3, pp. 313-334, 1990.

[66] J. Li and L. Li, On the critical success factors for B2B e-marketplace, in Proceedings of the $7^{\text {th }}$ International Conference on Electronic Commerce, Xi'an, China, 2005, pp. 119-122.

[67] G. Longworth, Designing Systems for Change. New Jersey: Wiley-Blackwell, 1985.

[68] Jr. H. C. Lucas and M. Olson, The impact of information technology on organizational flexibility, Journal of Organizational Computing and Electronic Commerce, vol. 4, no. 2, pp. 155-176, 1994.

[69] M. Lycett, R. D. Macredie, C. Patel, and R. J. Paul, Migrating agile methods to standardized development practice, Computer, vol. 36, no. 6, pp. 79-85, 2003.

[70] J. Michie and M. Sheehan, Business strategy, human resources, labour market flexibility and competitive advantage, The International Journal of Human Resource Management, vol. 16, no. 3, pp. 445-464, 2005.

[71] M. Muffatto and A. Payaro, Implementation of e-procurement and e-fulfillment processes: A comparison of cases in the motorcycle industry, International Journal of Productions Economics, vol. 89, no. 3, pp. 339-351, 2004.

[72] J. Nakane and R. W. Hall, Holonic manufacturing: Flexibility-the competitive battle in the 1990s, Production Planning \& Control, vol. 2, no. 1, pp. 2-13, 1991.

[73] K. Nelson and M. Ghods, Measuring technology flexibility, European Journal of Information Systems, vol. 7, no. 4, pp. 232-240, 1998

[74] K. M. Nelson, H. J. Nelson, and M. Ghods, Technology flexibility: Conceptualization, validation, and measurement, in Proceedings of the $13^{\text {th }}$ Hawaii International Conference, Hawaii, USA, 1997, pp. 76-87.

[75] C. H. Nilsson and H. Nordahl, Making manufacturing flexibility operational-part 2: Distinctions and an example, Integrated Manufacturing Systems, vol. 6, no. 2, pp. 4-10, 1995.

[76] D. Ong, Putting B2B hype in perspective, Business Times (Singapore), vol. 8, April 3, pp. 5-8, 2000.

[77] M. V. Oosterhout, E. Waarts, E. V. Heck, and J. V. Hillegersberg, Business agility: Need, readiness and alignment with IT strategies, in Agile Information Systems: Conceptualization, Construction, and Management (K. C. Desouza, Ed.). Burlington, USA: Elsevier, 2007, pp. 52-69.

[78] M. Ozer, The role of flexibility in online business, Business Horizons, vol. 45, no. 1, pp. 61-69, 2002.

[79] M. Pagell and D. R. Krause, A multiple-method study of environmental uncertainty and manufacturing flexibility, Journal of Operations Management, vol. 17, no. 3, pp. 307-325, 1999.

[80] R. Palanisamy, Strategic information systems planning model for building flexibility and success, Industrial Management \& Data Systems, vol. 105, no. 1, pp. 63-81, 2005.

[81] R. Parthasarthy and S. P. Sethi, Relating strategy and structure to flexible automation: A test of fit and performance implications, Strategic Management Journal, vol. 14, no. 7, pp. 529-549, 1993.

[82] C. C. Poirier and M. J. Bauer, E-Supply Chain: Using the Internet to Revolutionize your Business: How Market Leaders Focus their Entire Organization on Driving Value to Customers. California: Berrett-Koehler Publishers, 2000.

[83] W. D. Presutti, Supply management and e-procurement: Creating value added in the supply chain, Industrial Marketing Management, vol. 32, no. 3, pp. 219-226, 2003.

[84] T. Puschmann and R. Alt, Successful use of e-procurement in supply chains, Supply Chain Management: An International Journal, vol. 10, no. 2, pp. 122-133, 2005.

[85] M. Rask and H. Kragh, Motives for e-marketplace participation: Differences and similarities between buyers and suppliers, Electronic Markets, vol. 14, no. 4, pp. 270-283, 2004

[86] M. H. Safizadeh, L. P. Ritzman, D. Sharma, and C. Wood, An empirical analysis of the product-process matrix, Management Science, vol. 42, no. 11, pp. 1576-1591, 1996.

[87] B. R. Sarker, S. Krishnamurthy, and S. G. Kuthethur, A survey and critical review of flexibility measures in manufacturing systems, Production Planning \& Control, vol. 5, no. 6, pp. 512-523, 1994

[88] A. K. Sethi and S. P. Sethi, Flexibility in manufacturing: A survey, International Journal of Flexible Manufacturing Systems, vol. 2, no. 4, pp. 289-328, 1990.

[89] N. Slack, The flexibility of manufacturing systems, International Journal of Operations \& Production Management, vol. 7, no. 4, pp. 35-45, 1993.

[90] A. Smart and A. Harrison, Online reverse auctions and their role in buyer-supplier relationships, Journal of Purchasing and Supply Management, vol. 9, no. 5-6, pp. 257-268, 2003.

[91] C. Soh, M. L. Markus, and K. H. Goh, Electronic marketplaces and price transparency: Strategy, information technology, and success, Management Information Systems Quarterly, vol. 30, no. 3, pp. 705-723, 2006.

[92] R. A. Sommer, Business process flexibility: A driver for outsourcing, Industrial Management \& Data Systems, vol. 103, no. 3, pp. 177-183, 2003. 
[93] J. Y. Son and I. Benbasat, Organizational buyers' adoption and use of B2B electronic marketplaces: Efficiencyand legitimacy-oriented perspectives, Journal of Management Information Systems, vol. 24, no. 1, pp. 55-99, 2007.

[94] J. Y. Son, L. Tu, and I. Benbasat, A descriptive content analysis of trust-building measures in B2B electronic marketplaces, Communications of the Association for Information Systems, vol. 18, no. 1, pp. 6-6, 2006.

[95] S. Standing, C. Standing, and P.E.D. Love, A review of research on e-marketplaces 1997-2008, Decision Support Systems, vol. 49, no. 1, pp. 41-51, 2010.

[96] R. Stockdale and C. Standing, A framework for the selection of electronic marketplaces: A content analysis approach, Internet Research, vol. 12, no. 3, pp. 221-234, 2002.

[97] R. Stockdale and C. Standing, Benefits and barriers of electronic marketplace participation: An SME perspective, Journal of Enterprise Information Management, vol. 17, no. 4, pp. 301-311, 2004.

[98] F. F. Suarez, M. A. Cusumano, and C. H. Fine, An empirical study of manufacturing flexibility in printed circuit board assembly, Operations Research Letters, vol. 44, no. 1, pp. 223-240, 1996.

[99] C. Subramaniam and M. J. Shaw, A study of the value and impact of B2B e-commerce: The case of web-based procurement, International Journal of Electronic Commerce, vol. 6, no. 4, pp. 19-40, 2002.

[100]P. M. Swamidass and W. T. Newell, Manufacturing strategy, environmental uncertainty and performance: A path analytic model, Management Science, vol. 33, no. 4, pp. 509-524, 1987.

[101]E. Tetteh and J. Burn, Global strategies for SME-business: Applying the SMALL framework, Logistics Information Management, vol. 14, no. 1/2, pp. 171-180, 2001.

[102]D. M. Upton, Flexibility as process mobility: The management of plant capabilities for quick response manufacturing, Journal of Operations Management, vol. 12, no. 3-4, pp. 205-224, 1995.

[103]D. M. Upton, Process range in manufacturing: An empirical study of flexibility, Management Science, vol. 43, no. 8, pp. 1079-1092, 1997.

[104]M. Vizard. (2001, February) Building up an e-business block by block. InfoWorld. [Online]. Available: http://www.itworld.com/IW010226hnctointerview.

[105] R. J. Vokurka and S. W. O'Leary-Kelly, A review of empirical research on manufacturing flexibility, Journal of Operations Management, vol. 18, no. 4, pp. 485-501, 2000.

[106] H. W. Volberda, Building the Flexible Firm: How to Remain Competitive. Oxford: Oxford University Press, 1999.

[107]S. Wang, Building trust in business-to-business electronic marketplaces, presented at the IEEE International Conference on Service Operations and Logistics, and Informatics, Beijing, China, October 12-15, 2008, pp. 700-705.

[108]P. T. Ward and R. Duray, Manufacturing strategy in context: Environment, competitive strategy and manufacturing strategy, Journal of Operations Management, vol. 18, no. 2, pp. 123-138, 2000.

[109]B. Wernerfelt and A. Karnani, Competitive strategy under uncertainty, Strategic Management Journal, vol. 8, no. 2, pp. 187-194, 1987.

[110]D. M. Zelenovic, Flexibility-a condition for effective production systems, International Journal of Production Research, vol. 20, no. 3, pp. 319-337, 1982.

[111] G. J. Zenz, Purchasing and the Management of Materials. New York: John Wiley \& Sons, 1994. 